\title{
The Effect of Male Size and Sex Ratio on the Duration of Precopulatory Mate Guarding in the Hermit Crab Pagurus filholi
}

\author{
Shingo Minouchi and Seiji Goshima \\ Department of Marine Biological Science, Faculty of Fisheries, Hokkaido University, \\ Hakodate 041-8611, Japan
}

\begin{abstract}
In the precopulatory phase, a male hermit crab Pagurus filholi guards a female by pinching the rim of the female's shell with his cheliped. We conducted two experiments to clarify the influences of the male-female size ratio and the sex ratio on the duration of precopulatory mate guarding. Larger males guarded females earlier and, consequently, performed longer precopulatory guarding than smaller males. Possible causes for these differences may include loading constraints (i.e. larger males appear to have a lower cost of mate guarding) and a size dependent conditional mating strategy (i.e. smaller males copulate without performing precopulatory mate guarding). Males also guarded females earlier and longer as the sex ratio became more male biased. When the male : female ratio increases, the chance of finding a female that will soon spawn may decrease, and intrasexual competition for the few receptive females may increase; under such circumstances, males may guard females that are not yet ready to mate. Relative male size and the sex ratio significantly affected the amount of time a male guarded a female. These results suggest that males might assess both female size and the sex ratio when deciding when to guard a female.
\end{abstract}

Key words: hermit crab, male size, mating behavior, Pagurus filholi, precopulatory guarding, sex ratio

\section{INTRODUCTION}

Animals behave to maximize their mating success. For species in which many males compete for females, males may evolve elaborate morphological and behavioral traits to increase their fitness. Selection for traits that are solely concerned with increasing mating success is usually referred to as sexual selection (Krebs \& Davies 1993). When a male finds a mature female, he of ten guards her before spawning to prevent other males from mating with her. Such precopulatory mate guarding behavior is particularly widespread among crustaceans (e.g. Ridley 1983; Bauer \& Martin 1991). In

Received March 13, 2000: Accepted May 2, 2000

* Corresponding author. Present address: Aquamuseum, Yokohama Hakkeijima Sea Paradise, Yokohama 2360006, Japan. many cases, hard-shelled males guard premolt females by carrying them for up to several days until they spawn. This behavior allows males to improve their chance of reproductive success, since the final male to mate has the best chance of fertilizing a female's eggs (Koga et al. 1993; Goshima et al. 1996a, 1998).

The duration of precopulatory guarding varies for different crustacean species (Ward 1983; Wada et al. 1999). Optimal guarding time may be affected by numerous factors. As the energetic cost of carrying a female is higher for a small male than for a large male, a large male can guard a female for a longer time before spawning than a small male can (Elwood \& Dick 1990 ). If there is a large male-biased operational sex ratio in the population, male-male competition for females will increase. Under such conditions, males should initiate guarding behavior earlier, even if the females are not fully mature (Yamamura 1987). 
Pagurus filholi (de Man) (formerly P. geminus McLaughlin) is a common hermit crab in the intertidal rocky shore of Hokkaido in northern Japan. During the precopulatory phase, males of the genus Pagurus (Paguridae) grasp and drag females by pinching the rim of the female's shell with his left minor cheliped (Imafuku 1986; Goshima et al. 1996b; Wada et al. 1996; Goshima et al. 1998). Male P. filholi can ensure their paternity by securing their mates from other males until the female can copulate and spawn (Goshima et al. 1998). This guarding behavior can easily be measured, so this behavior is convenient when clarifying the effects of population parameters on male guarding duration.

In this study, attention was focused on the effect of the male-female size ratio and sex ratio on precopulatory mate guarding. The male-female size ratio affects the hermit crab mating behavior (Minouchi \& Goshima 1998). We predict that the precopulatory mate guarding period of a large male is longer than that of a small male because of energetic loading (Elwood \& Dick 1990). Reproductive behavior is also affected by spatial and potential changes in the operational sex ratio (Manning 1980; Dick \& Elwood 1996; Wada et al. 1999). We also predict that the length of the precopulatory mate guarding period of $P$. filholi is longer when the sex ratio is male biased. To test these predictions, we conducted two experiments to clarify the influences of the male-female size ratio and the sex ratio on the length of the precopulatory mate guarding period.

\section{MATERIALS AND METHODS}

We collected $P$. filholi from the intertidal rocky shore at Kattoshi ( $\left.41^{\circ} 44^{\prime} \mathrm{N}, 140^{\circ} 36^{\prime} \mathrm{E}\right)$, located in the southwestern part of Hakodate Bay, Hokkaido, Japan. A detailed description of the study area is given by Wada et al. (1995) and Goshima et al. (1996b). Sampling was carried out by lifting or turning over stones and cobbles by hand during low tide. The reproductive biology of $P$. filholi can be summarized as follows, based on Goshima et al. (1998). The main spawning months of $P$. filholi are from March to July. Precopulatory mate guarding behavior is observed in the field from late January to early September. Males are larger than females, and the size variance of males is greater than for females. Males and females do not always molt before copulating. The mate guarding behavior may last for up to 5 days in the field. Females lay eggs several times within a breeding season. Eggs are attached to the female's pleopods. At water temperature of $21.5^{\circ} \mathrm{C}$, females incubate their eggs for approximately 16 days. Clutch size increases with body size, and large females can carry up to 200 eggs. Larger males can seize females that are being guarded by smaller males.

Solitary hermit crabs (i.e. those not in pairs) were collected between April and June 1996. Experiments were conducted at the Usujiri Fisheries Laboratory, Hokkaido University. The sexes were separated and kept in stock tanks under natural conditions in the laboratory before each experiment. The crabs were fed fish food every other day and algae (Sargassum thunbergii) once a week.

We observed the female gonad condition through the thin skin of the abdomen to assess maturity. In the experiments, we used females whose gonads were not full with unfertilized eggs and females that were carrying pre-hatching eggs attached to their pleopods. Females in both of these conditions cannot copulate immediately.

Experimental replicates were run in plastic tanks $(40 \times 30 \times 15 \mathrm{~cm}$ in height $)$ containing sand and a few round stones. We placed a given number of males and females in the experimental tanks depending on each experiment. A number and size of individuals for each experiment will be mentioned in each section below. Observations were made every 6 hours for a week (a small headlight was used at night). We checked the crabs to see if males guarded females. When a pair formed, they were transferred to another individual small tank and checked at each observation to see if the female spawned when the male finished guarding. Guarding was considered to start 3 hours before the first observation of pair formation. Guarding duration was estimated as the duration from the start of guarding to spawning.

The experimental conditions were constant for all treatments $\left(12^{\circ} \mathrm{C}\right.$ water temperature and 12 hour light : 12 hour dark light cycle). To maintain the same population structure during each experiment, if a pair was removed, we put another male and female (not a guarding pair) into the experimental tank. If the guarding male stopped grasping the female and the female did not lay eggs, the pair was returned to the experimental tank. At the end of each experimental week, all females in the experimental tank were checked for the presence of eggs on the pleopods. After each experiment, their shield lengths (SL: hard portion of carapace) were measured with a stereoscopic microscope. 


\section{Male-female size ratio experiment}

The first experiment examined the effect of the malefemale size ratio on the mean guarding time. Two treatments were conducted, with four replicates per treatment. Each treatment had 10 males and $10 \mathrm{fe}$ males. Males in the first treatment were larger (size range $=3.0$ to $7.2 \mathrm{~mm} \mathrm{SL}$ ) than males in the second treatment (size range $=2.0$ to $3.5 \mathrm{~mm} \mathrm{SL}$ ). The mean size $( \pm \mathrm{SE}$ ) of males was significantly different between the two treatments (large-male treatment: $x=$ $4.66 \pm 0.11 \mathrm{~mm}, n=65$; small-male treatment: $x=2.67$ $\pm 0.05 \mathrm{~mm}, n=56$; Mann-Whitney $U$-test, $U=17.5, P$ $<0.01)$, while the mean female size $( \pm \mathrm{SE})$ was similar (large-male treatment: $x=2.13 \pm 0.03 \mathrm{~mm}, n=64$; small-male treatment: $x=2.19 \pm 0.03 \mathrm{~mm}, n=56$; Mann-Whitney $U$-test, $U=1543.0, P>0.1$ ).

\section{Sex ratio experiment}

The second experiment examined the effect of the sex ratio on the mean guarding time at three male : female sex ratios $(5: 15,10: 10$, and $15: 5)$. Twenty individuals were maintained in each tank. We performed three replicates per treatment. To eliminate the ef fect of size, similarly sized males and similarly sized females were used in all treatments (male size: $5: 15, x=3.92 \pm 0.10$ $\mathrm{mm}, n=31 ; 10: 10, x=3.87 \pm 0.09 \mathrm{~mm}, n=45 ; 15: 5$, $x=3.67 \pm 0.06 \mathrm{~mm}, n=55$; Kruskal-Wallis test, $H=$ 5.963, d.f. $=2, P>0.05$; female size: $5: 15, x=2.21$ $\pm 0.03 \mathrm{~mm}, n=61 ; 10: 10, x=2.26 \pm 0.03 \mathrm{~mm}, n=46$; $15: 5, x=2.22 \pm 0.04 \mathrm{~mm}, n=24$; Kruskal-Wallis test, $H=3.339$, d.f. $=2, P>0.1$ ).

\section{RESULTS}

\section{Male-female size ratio experiment}

Guarding duration varied from 3 to $69 \mathrm{~h}$ in the largemale treatment and $3-51 \mathrm{~h}$ in the small-male treatment. The mean guarding duration $( \pm \mathrm{SE}$ ) of large males $(x=21.62 \pm 2.83 \mathrm{~h}, n=39)$ was significantly longer than that of small males $(x=12.09 \pm 2.08 \mathrm{~h}, n$ = 33; Mann-Whitney $U$-test, $U=419.5, P<0.05$, Fig. $1)$. During the first 6 -hour pre-copulatory guarding period, 14 females in the small-male treatment and $8 \mathrm{fe}$ males in the large-male treatment copulated and spawned.

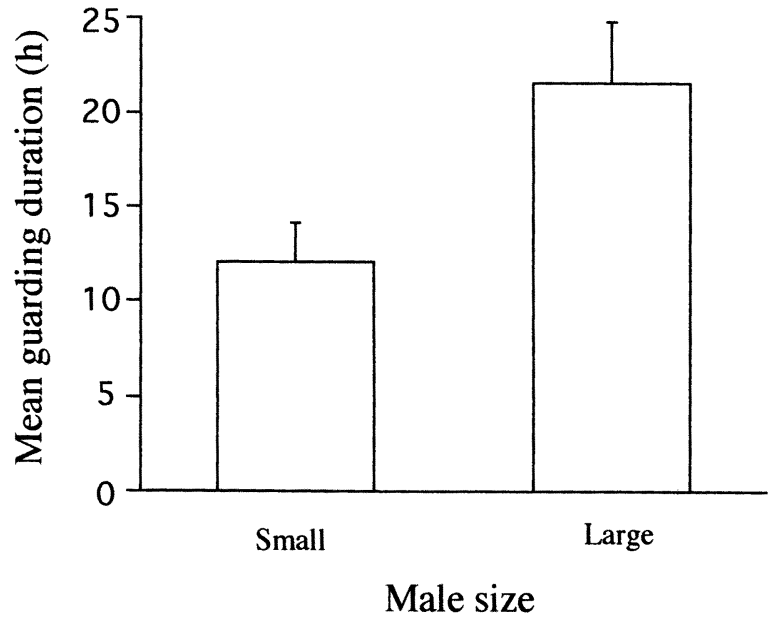

Fig. 1. Results of male-female size ratio experiment. Precopulatory mate guarding duration of large and small males at 6 -h intervals. Vertical bars indicate SE of the mean.

\section{Sex ratio experiment}

Guarding duration varied from 3 to 39,3 to 81 , and 3 to $45 \mathrm{~h}$ in the $5: 15,10: 10$, and $15: 5$, male : female sex ratios, respectively. Male guarding duration increased significantly as the male : female sex ratio increased (male : female sex ratio $=5: 15, x=17.28 \pm 2.57 \mathrm{~h}, n$ $=29 ; 10: 10, x=27.72 \pm 3.72 \mathrm{~h}, n=25 ; 15: 5, x=32.20$ $\pm 3.36 \mathrm{~h}, n=15$; Kruskal-Wallis test, $H=10.739$, d.f. $=2, P<0.01$, Fig. 2).

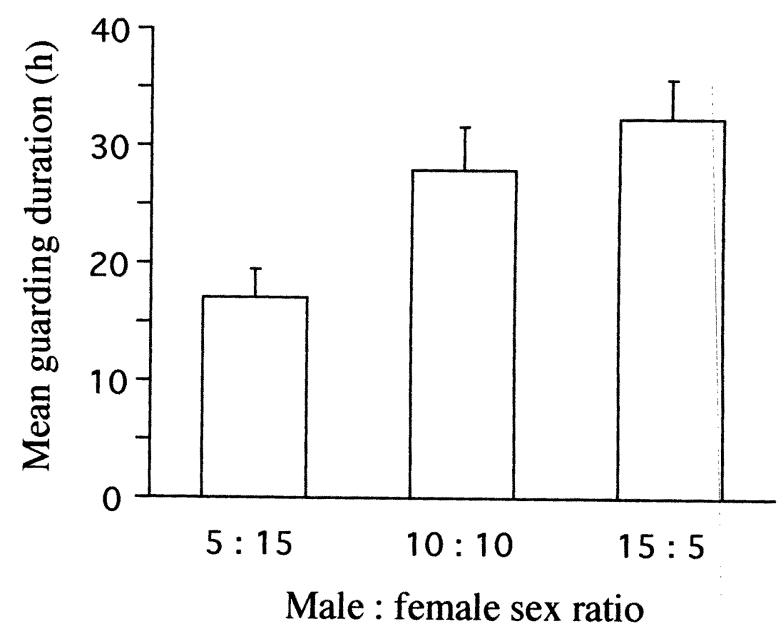

Fig. 2. Results of sex ratio experiment. Precopulatory mate guarding duration at different sex ratio (male : female $=5: 15 ; 10: 10 ; 15: 5$ ) observed at 6 -h intervals. Vertical bars indicate SE of the mean. 


\section{DISCUSSION}

Variance in the frequency of mating depends on extrinsic factors, such as the operational sex ratio (Vepsä lä inen \& Savolainen 1995; Wada et al. 1999) and encounter rate between males and females (Wada et al. 1999), and intrinsic factors, such as body size (Henmi et al. 1993; Meeren 1994; Wada et al. 1999). This study shows that in $P$. filholi, male size and sex ratio significantly affect the male investment in precopulatory mate guarding.

Males incur many costs during pre-copulatory mate guarding. Pairs in precopulatory mate guarding may suffer a higher level of predation than single animals (Ward 1986). Males must expend energy to guard females (Elwood \& Dick 1990), and precopulatory mate guarding pairs may be unable to forage efficiently. These costs, however, are not the same for all males. It appears that the guarding cost increases as the malefemale size ratio decreases because of the increasing energy required to guard larger females.

In this study, larger males performed longer precopulatory guarding than smaller ones (Fig. 1). There are two possible explanations for this difference. First, larger males appear to have a lower cost of precopulatory mate guarding, due to lower loading constraints (Adams \& Greenwood 1983), and precopulatory mate guarding by larger males may be less costly than the energy required to attack and displace a guarding male (Iribarne et al. 1995). Second, it appears that smaller males copulate without performing precopulatory mate guarding behavior. In $P$. filholi, the mating behavior sequence differs depending on the male/female size ratio, and the choice of behavior might be a conditional strategy (Minouchi \& Goshima 1998). Such conditional mating strategy might also explain why smaller males performed shorter precopulatory guarding, and females in the small-male treatment frequently carried eggs on their pleopods within the first 6 -h guarding period in the male-female size ratio experiment. However, based on the present data, we cannot determine if this phenomenon is caused by a loading constraint, a conditional strategy, or both.

Precopulatory guarding time increases when the operational sex ratio becomes more male-biased in the ESS theoretical model (Grafen \& Ridley 1983; Yamamura 1987) and cost-benefit analyses (Elwood \& Dick 1990). If the guarding time is affected only by male size (guarding cost), there should have been no difference in the guarding time among the different sex ratios, since there was no size difference in either sex among the sex ratio treatments. As the ratio of the number of males to females increased, the mate guarding duration also increased (Fig. 2). When the proportion of males in the population is high, most females that will soon be receptive to mate are quickly detected and guarded by males (Manning 1980). Intrasexual competition for the few receptive females is intensified in male-biased populations, so males also guard females that still need a long period before they will be ready to mate (e.g. Goshima et al. 1996a).

The present study clarified that the male size and sex ratio affect the duration that a male $P$. filholi guards a female. However, male reproductive response is also dependent on the relative size of other males in an amphipod (Iribarne et al. 1995) and P. middendorffii (Wada et al. 1999). Male size variance of $P$. filholi is high in the field (Minouchi \& Goshima 1998). Thus male-male interaction may affect the precopulatory mate guarding duration. More data is needed to clarify the effect of male size in the population on mate guarding.

Acknowledgments. We thank S. Nakao, T. Noda, S. Wada, K. Ito, T. Sonoda and other members of the Laboratory of Benthology, Faculty of Fisheries, Hokkaido University for their valuable comments and criticisms. We also thank Y. Arashida and other staff of the Usujiri Fisheries Laboratory, Faculty of Fisheries, Hokkaido University for their help during the experiments. We are grateful to S. Hughes and M. Nader for their helpful comments on the manuscript. Cordial thanks are also given to J. R. Bower of Hokkaido University for improving the English of this manuscript. We are also especially grateful to K. Wada and an anonymous referee for their useful suggestions on the manuscript.

\section{REFERENCES}

Adams, J. and P. J. Greenwood 1983. Why are males bigger than females in pre-copula pairs of Gammarus pulex? Behavioral Ecology and Sociobiology, 13: 239241

Bauer, R. T. and J. W. Martin (ed.) 1991. Crustacean Sexual Biology. Columbia University Press, New York, 355 pp.

Dick, J. T. A. and R. W. Elwood 1996. Effects of natural variation in sex ratio and habitat structure on mateguarding decisions in amphipods (Crustacea). 
Behaviour, 133: 985-996.

Elwood, R. and J. T. Dick 1990. The amorous Gammarus : the relationship between precopula duration and sizeassortative mating in G. pulex. Animal Behaviour, 39: 828-833.

Goshima, S., T. Koga and M. Murai 1996a. Mate acceptance and guarding by male fiddler crabs Uca tetragonon (Herbst). Journal of Experimental Marine Biology and Ecology, 196: 131-143.

Goshima, S., S. Wada and H. Ohmori 1996b. Reproductive biology of the hermit crab Pagurus nigrofascia (Anomura: Paguridae). Crustacean Research, 25: 86-92.

Goshima, S, T. Kawashima and S. Wada 1998. Mate choice by males of the hermit crab Pagurus filholi: Do males assess ripeness and/or fecundity of males? Ecological Research, 13: 151-161.

Grafen, A. and M. Ridley 1983. A model of mate guarding. Journal of Theoretical Biology, 102: 549-567.

Henmi, Y., T. Koga and M. Murai 1993. Mating behavior of the sand bubbler crab Scopimera globosa. Journal of Crustacean Biology, 13: 736-744.

Imafuku, M. 1986. Sexual discrimination in the hermit crab Pagurus geminus. Journal of Ethology, 4: 39-47.

Iribarne, O., M. Fernandez and D. Armstrong 1995. Precopulatory guarding-time of the male amphipod Eogammarus oclairi: effect of population structure. Marine Biology, 124: 219-223.

Koga, T., Y. Henmi and M. Murai 1993. Sperm competition and the assurance of underground copulation in the sand-bubbler crab Scopimera globosa (Brachyura: Ocypodidae). Journal of Crustacean Biology, 13: 134137

Krebs, J. R. and N. B. Davies 1993. An Introduction to Behavioural Ecology (3rd ed.). Blackwell Science, Oxford, $420 \mathrm{pp}$.

Manning, J. T. 1980. Sex ratio and optimal male time investment strategies in Asellus aquaticus (L.) and $A$. meridianus Racovitza. Behaviour, 74: 264-273.
Meeren, G. I. V. D. 1994. Sex- and size-dependent mating tactics in a natural population of shore crabs Carcinus maenas. Journal of Animal Ecology, 63: 307-314.

Minouchi, S. and S. Goshima 1998. Effect of male/female size ratio on mating behavior of the hermit crab Pagurus filholi (Anomura: Paguridae) under experimental conditions. Journal of Crustacean Biology, 18: 710-716.

Ridley, M. 1983. The Explanation of Organic Diversity. Claredon Press, Oxford, $272 \mathrm{pp}$.

Vepsäläinen, K. and R. Savolainen 1995. Operational sex ratios and mating conflict between the sexes in the water strider Gerris lacustris. American Naturalist, 146: 869-880.

Wada S., S. Goshima and S. Nakao 1995. Reproductive biology of the hermit crab Pagurus middendorffii Brandt (Decapoda: Anomura: Paguridae). Crustacean Research, 24: 23-32.

Wada, S., T. Sonoda and S. Goshima 1996. Temporal size covariation of mating pairs of the hermit crab Pagurus middendorffii (Decapoda: Anomura: Paguridae) during a single breeding season. Crustacean Research, 25: 158-164.

Wada, S., K. Tanaka and S. Goshima 1999. Precopulatory mate guarding in the hermit crab Pagurus middendorffii (Brandt) (Decapoda: Paguridae): effects of population parameters on male guarding duration. Journal of Experimental Marine Biology and Ecology, 239: 289-298.

Ward, P. I. 1983. Advantage and a disadvantage of large size for male Gammarus pulex (Crustacea: Amphipoda). Behavioral Ecology and Sociobiology, 14: 69-76.

Ward, P. I. 1986. A comparative field study of the breeding behavior of a stream and a pond population Gammarus pulex (Amphipoda). Oikos, 46: 29-36.

Yamamura, N. 1987. A model on correlation between precopulatory guarding and short receptive to copulation. Journal of Theoretical Biology, 127: 171-180. 